\title{
Panel backs closure of US fusion machine
}

Washington. The largest fusion machine in the United States should be closed down next year, and the national fusion research programme refocused on basic plasma physics and materials science, according to a key advisory committee to the Department of Energy (DoE).

These conclusions, which would mean the closure of the Tokamak Fusion Test Reactor (TFTR) at Princeton, New Jersey, were formally presented by the DoE's Fusion Energy Advisory Committee (FEAC) to Martha Krebs, director of its Office of Energy Research, on 27 January. They were immediately accepted by Krebs and, as the likely basis of a scaled-back US fusion research programme, are due to be considered by Congress in a series of hearings planned to take place in Washington next month.

The US fusion budget was cut back by one-third in the current financial year to $\$ 244$ million, when the Tokamak Physics Experiment (TPX), a major new experiment planned for the Princeton Plasma Physics Laboratory (PPPL), was cancelled by Congress (see Nature 377, 567; 1995).

For the next financial year, which starts in October, the Clinton administration is expected to propose a budget of about $\$ 250$ million, or slightly higher. Congress, having singled out fusion for attack last year, may accept the administration's budget proposal this time - provided, according to Congressional staff members, that the fusion community agrees on how it should be spent.

FEAC's proposal would allow the United States' other two large tokamak facilities, namely General Atomics' DIII-D machine at San Diego, and the C-Mod Alcator tokamak at the Massachusetts Institute of Technology, to operate at high levels of utilization.

It would also allow the US to continue participating in the design phase of the International Thermonuclear Experimental Reactor (ITER) up to the completion of this phase in 1998, and for a modest expansion in support for small university teams working on plasma physics and materials science.

But according to FEAC, if the fusion budget is set at $\$ 250$ million, TFTR could only operate briefly during 1997 before closing down for good, a year earlier than planned. The advisory committee adds that PPPL, of which TFTR is the centrepiece, is "a critical national resource for the fusion programme" and must be retained. "We can't imagine the programme without it," says Mike Knotek of the Batelle Pacific Northwest Laboratories, chair of the panel which drafted the committee's report.

Many fusion scientists, however, doubt that PPPL can keep its leadership role after TFTR shuts down. The laboratory is there- fore planning to continue to press for the retention of TFTR, at least until 1998. It argues that there are valuable experiments, especially concerning the sheared flow of plasma and using deuterium-tritium plasmas, which no other machine in the world can perform.

Dale Meade, deputy director of the laboratory, says that TFTR could continue to operate within a $\$ 250$-million budget, and that the only purpose of its early closure would be to appease Congress's desire for a sacrificial lamb. "If you want to maximize

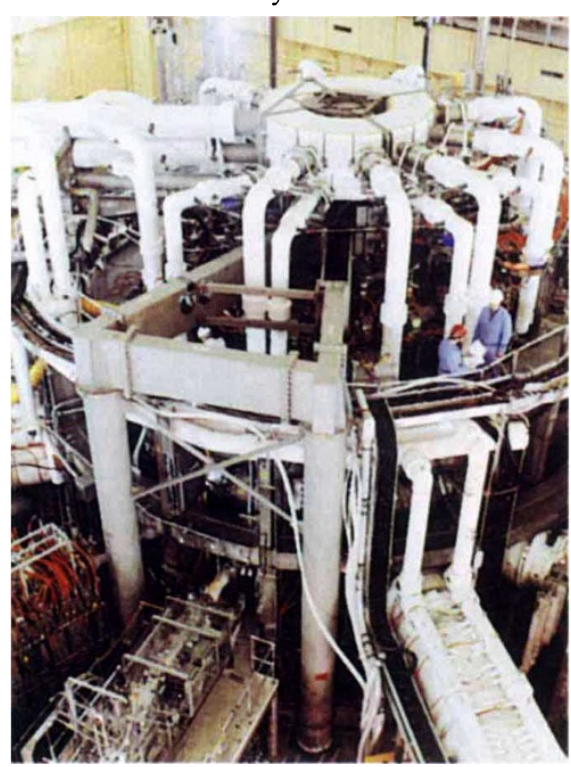

Threatened: the Tokamak Fusion Test Reactor at Princeton would close under the plan.

the best science, you can run it with the budget at \$250 million," says Meade. "If you want to maximize the pain and suffering, you say that you can't run it."

FEAC was asked to review the fusion programme in December, when the energy department was considering fusion budgets as low as $\$ 200$ million, and to present proposals for a range of programmes costing $\$ 200$ million, \$225 million, \$250 million and $\$ 275$ million respectively. Since then, however, the White House is said to have told Hazel O'Leary, the energy secretary, to put more money into fusion, and as a consequence, next month's budget proposal is expected to include a request for at least $\$ 250$ million.

As a result, the advisory committee declined to offer programmes at the lower two levels, saying merely that these would wreck the programme by endangering participation in ITER and forcing the closure of either DIII-D or C-Mod. It did offer a programme at $\$ 250$ million, and promised a much stronger programme if $\$ 275$ million were to be made available.

David Baldwin, senior vice president of DIII-D, endorsed the $\$ 250$-million proposal, but told the panel that it was promising too much for $\$ 275$ million. "Your justification for the $\$ 275$ million is very weak," he said, adding that it was "incredible" to argue, as the committee had done, that an extra $\$ 25$ million would buy prolonged operation of TFTR, greater participation in ITER, and a stronger university science programme.

The FEAC report strongly endorsed continued US support for the design phase of ITER, while accepting that the United States is unlikely to be able to contribute much towards its construction.

Two members of the panel — James Thompson, a former director of PPPL, and Joseph Gavin, former president of Grumman Aerospace - dissented, arguing for a speedy withdrawal from ITER on the grounds that the country has no reputation left to lose as an international scientific partner, and that the machine itself will never be built. But the panel, led by Robert Conn of the University of California at San Diego, ruled that the ITER design phase should remain a top priority of the US programme - whether or not the machine itself is ever built.

The panel also called for another "review" of the US inertial confinement fusion efforts, the main alternative to magnetic fusion. But William Barletta, director of fusion at the Lawrence Berkeley Laboratory in California, where most of such research is done, accused Conn of "looking for a reason to assassinate" his programme. He expressed confidence that the Department of Energy would continue its support of the alternative work.

At the same time, Anne Davies, head of the Office of Fusion Energy at the DoE, said that the advisory committee was being optimistic about what could be achieved with $\$ 250$ million. She estimated that what it proposed at that level, including some operation of TFTR in 1997, would actually cost $\$ 265$ million.

"I don't think we can run TFTR next year if our budget is $\$ 250$ million," she said. At \$225 million, she added, “I don't think the programme will survive, because it will be so divisive. It will unravel." However, Krebs said that the panel had proposed a programme, "particularly at the $\$ 250$-million level", which she would support.

The structure of the US fusion programme - with three large domestic facilities chasing a shrinking pot of money while watching ITER drift to the top of the priority list - has led to bitter and occasionally public infighting in recent years, further undermining support for the field. "Something I can't over-emphasize is the need for community consensus," said Knotek. "The big message we received from Capitol Hill was that consensus is worth $\$ 50$ million to you," he added.

Colin Macilwain 